\title{
THE DIDACTICAL USE OF TABLETS: A BALANCING ACT BETWEEN TEACHER-CENTRED AND LEARNER-CENTRED EDUCATION
}

\author{
H. Montrieux, T. Schellens \\ Ghent University (BELGIUM)
}

\begin{abstract}
In the past decade, the use of tablet devices has seen an uptake in education. This is because in addition to its instrumental value - being lightweight and serving as an all-in-one-device - it can foster more active and learner-centred approaches. While short-term studies have begun examining the added value of these tools, tablets should be studied from a multi-stakeholder perspective and over a longer period of time. Unfortunately, such research remains lacking. In this research, we questioned the use of tablet devices in classes over a period of five years, as perceived by both students and teachers. Data collection took place in a school that has since 2012 replaced books with tablet devices in all classrooms in the entire organisation, and involved all teachers $(N=83)$ and students $(N=694)$. Four waves of data collection took place: a pre-adoption test in 2012, two follow-up measurements, and finally, a post-adoption test in 2016. The questionnaires were based on the instructional strategies typology of Hoogeveen and Winkels, which includes five different instructional strategies from more teacher-centred approaches. These include and range from presenting lectures using the tablets, to more learner-centred approaches such as tablet-based assignments, interactive exercises, gamebased learning, and collaborative learning. In addition, the impact of individual-related and contextrelated teacher variables were included in the analysis. The results indicate a discrepancy between both teachers' and students' initial high expectations, and the actual use of these devices for learnercentred approaches. Moreover, results show that over the different data collection periods, time was significant for both teachers and students. For teachers, the results indicate that prior expectations about using tablets for more learner-centred approaches were, following a decline in follow-up studies, met after five years. For students, pre-adoption expectations related to the five instructional strategies were significantly higher, compared to the other three measurement moments. However, learnercentred approaches interaction, assignments, and collaboration were significantly higher in the postadoption test, compared to the two follow-up measurements. Furthermore, a balance was found between the use of teacher-centred and learner-centred instructional strategies in the post-adoption test. Finally, the employed instructional strategies were influenced by individual-related and contextrelated teacher variables, such as teachers' age and grade they taught. These results indicate that while high expectations about the didactical use of tablets were not met in follow-up measurements, and tablets were primarily used to support teacher-centred education, and that this pattern changed over time. Moreover, in the post-adoption test, the use of learner-centred approaches arose. These results provide meaningful insight into the dynamic evolution of tablet use over a longer time period, which is a requirement for research evaluating the didactical value of this tool.
\end{abstract}

Keywords: tablet devices, instructional strategies, contextual variables, longitudinal study

\section{INTRODUCTION}

In the past decade, the use of tablet devices has seen an uptake in education. This is because in addition to its feature as an all-in-one-device [1], tablets can foster more learner-centred approaches $[2,3]$. Moreover, as they are detached from time and space constraints [4], make available a large number of applications, and provide wide access to a multitude of digital resources, tablets enable learner-centred approaches such as interactive hands-on assignment activities and collaborative learning $[5,6]$. While it can be argued that the use of technology during classes can support learner- 
centred didactical approaches, Ertmer et al. [7] indicate teachers as the true gatekeepers of technology-enhanced learning, as they have to integrate technology into their daily classroom practices. In practice, research has already highlighted that simply implementing technology in classes does not necessarily lead to a radical change in the didactic teaching methods of teachers $[3,8,9]$. Moreover, it appears that technology is often integrated in classrooms to support current traditional teaching practices $[8,10,11]$. According to Jonassen and Reeves [12], technology is best used when students use it as a cognitive partner to access and analyse information, and to interpret and represent the information to others. Moreover, available research states that technology should be used to accomplish authentic tasks and to facilitate authentic student learning, rather than backing-up existing classroom practice [7].

However, the paucity of available studies highlights the need for investigation into the actual use of tablets [13]. While the mainly qualitative analyses of the limited amount of available studies $[14,15]$ are valuable, quantitative studies about the implementation of tablet devices are lacking [1,11]. In addition, the available research states that teachers' experiences should be investigated from a longitudinal perspective, as it may take a number of years to accumulate relevant expertise [16]. In this light, Ifenthaler et al. [10] hypothesise in their research that teachers may develop expertise over a longer period of time and following intensive use, which may lead to a change towards more student-oriented teaching practice.

Regarding this pivotal role of the teacher, previous research in the field of technology-enhanced learning acknowledges the importance of taking individual characteristics of teachers into account $[17,18,19,20]$. More specifically, research shows that variables such as gender and age can have an influence on teachers' use of technology [21]. However, the literature on educational computing abounds with conflicting findings about the impact of gender [22]. While some research states that male teachers have more positive attitudes towards technology compared to female teachers [17], other research shows no direct effect of gender on technology integration [20], or even a negative relation between demographic characteristics and computer proficiency [21]. Furthermore, technologyrelated activities have been largely viewed and labelled as a 'male domain' [23]. Concerning more context-related variables, previous research indicates that teachers in upper grades were moderately more likely to use technology [24].

As the available research primarily reports the use of tablet devices for a relatively short time period, a novelty effect can partly explain the general positive reactions of both teachers and students towards the use of these tools [25]. Furthermore, while a number of studies are available concerning teachers' perceptions of the implementation of technology in the classroom, the perspectives of secondary school learners remain under-researched [26,27]. Moreover, while little research has involved experienced stakeholders [11], there is no research available that concurrently takes both the perspectives of teachers and students into account.

To address the aforementioned gaps in the current literature, the present research focuses on the fullscale implementation of tablets and its impact on the use of different instructional strategies, as evaluated by teachers and students in a Flemish secondary school that has used tablets since 2012 . As such, this study aims to investigate the didactical use - and a possible change in this use - over time. Moreover, the variables that can explain the didactical use of tablets are explored. The research questions that drove this study are:

Research question 1: Does the use of the different instructional strategies change over a time period of five years?

Research question 2: How are the tablets currently being used in the post-adoption measurement?

Research question 3: Is there a relation between the use of tablets and individual and contextual teacher characteristics? 


\section{METHODOLOGY}

\subsection{Participants and procedure}

This study was conducted in the first secondary school in Flanders that has implemented tablet devices (iPads) in all classrooms. At the start of the school year in 2012, each teacher and student was obliged to purchase a personal tablet for learning. This school introduced the tablet as a personal learning tool, with the aim of motivating and stimulating students to learn, by providing rich and relevant digital learning materials in the present digitised world. Four waves of data collection were performed: a pre-adoption online questionnaire that investigated the variables that explain participants' intention to use tablets (wave 1), and two follow-up questionnaires at the end of 2012 (wave 2), and 2013 (wave 3). Finally, five years after the initial implementation, a post-adoption questionnaire was conducted (wave 4). The data was collected during school time through an online application. During the first wave, 83 valid responses from teachers and 694 valid responses from students were collected compared to 66 valid responses from teachers and 633 valid responses from students in the second wave. In the third wave, 73 valid responses from teachers and 637 valid responses from students were obtained. Finally, in the fourth wave, 502 responses from students and 39 responses from teachers were gathered.

\subsection{Measurement}

The questionnaires were based on the instructional strategies typology of Hoogeveen and Winkels [28], which includes five different instructional strategies ranging from more teacher-centred approaches such as giving lectures using the tablets, to more learner-centred approaches such as tablet-based assignments, interactive exercises, game-based learning, and collaborative learning (see Table 1 for operationalisation). For each instructional format (instruction, interaction, game-based learning, collaborative learning, assignments), three or four concrete operationalisations were given to the students and teachers. They had to indicate whether or not they expected (first wave) or actually used (second, third, and fourth wave) the tablets during their courses for this specific operationalisation. For every instructional format, sum scores were calculated and weighed for the number of the given operationalisation in order to allow for comparison, resulting in five instructional method scales $(\min 0, \max 12)$. Cronbach's alphas were satisfactory $(>.70)$. In addition, teachers' background characteristics, comprising gender, age, and the grade in which they taught, were added to the questionnaires.

Table 1. The constructs of instructional strategies based on Hoogeveen and Winkels [28]

\begin{tabular}{|c|c|}
\hline $\begin{array}{l}\text { Instructional } \\
\text { strategy }\end{array}$ & Items \\
\hline Lecture & $\begin{array}{l}\text { 'Taking notes on the tablet during classes' } \\
\text { 'Reading books and texts on the tablet' } \\
\text { 'Watching movies to illustrate the course' } \\
\text { 'Watching pictures to illustrate the course' }\end{array}$ \\
\hline Interaction & $\begin{array}{l}\text { 'Online discussion about the learning content' } \\
\text { 'Exchange of information with peers' } \\
\text { 'Sharing learning content (e.g., using Dropbox)' } \\
\text { 'Sending exercises to the teacher in order of receive feedback' }\end{array}$ \\
\hline Assignment & $\begin{array}{l}\text { 'Completing homework using the tablet' } \\
\text { 'Completing exercises by searching for additional information on } \\
\text { the Internet' } \\
\text { 'Creating presentations, movies, etc.' }\end{array}$ \\
\hline Game & $\begin{array}{l}\text { 'Playing educational games' } \\
\text { 'Manipulating objects using the touch screens of the tablet' } \\
\text { 'Simulate learning content' }\end{array}$ \\
\hline Collaboration & $\begin{array}{l}\text { 'Group work' } \\
\text { 'Working together on projects' } \\
\text { 'Working together on problem-based projects' }\end{array}$ \\
\hline
\end{tabular}




\section{RESULTS}

\subsection{RQ1: Does the use of the different instructional strategies change over the time period of five years?}

Based on multivariate analysis, with the five measurement variables as dependent variables and 'wave' as independent variable, time was found to be significant for both students (Wilks' $\lambda=.79, F(15$, $6731)=39.23, p=.000)$ and teachers $($ Wilks' $\lambda=.81, F(15,660)=3.58, p=.000)$.

For students, all five instructional strategies changed significantly over time $(p<.05)$. Descriptive statistics (see Table 2) and pairwise comparisons using the Bonferroni test indicate that for the instructional strategy lecture, the mean score of the pre-adoption measurement was significantly higher, compared to the other three measurement moments $(p=.000)$. However, no significant difference was found between the two follow-up studies and the post-adoption measurement $(p>.05)$. Concerning the instructional strategy interaction, the pre-adoption expectations of the students were significantly higher compared to the other measurement times $(p=.000)$. However, while there was no difference between the follow-up measurements $(p=.527)$, the post-adoption measurement differed significantly from these follow-up studies $(p=.000)$. This indicates that the mean score of this strategy was significant higher after five years, compared to the second and third data collection, but that it was still lower compared to initial expectations. Regarding assignment, the mean score of the first measurement moment was also significantly higher, compared to the other three moments $(p=.000)$. In line with the instructional strategy interaction, no difference was found between wave 2 and wave 3 $(p=1.000)$, while the last wave was significantly higher compared to wave 2 and wave $3(p=.000)$. While prior-to-adoption expectations were significantly higher compared to the other three waves $(p=$ .000 ) for the instructional strategy game, no significant difference was found between the two followup measurements and the post-adoption measurement $(p>.05)$. Finally, for the instructional strategy collaboration, the expectations were again significantly higher when comparing them to the actual use of this strategy in the other three measurement moments $(p=.000)$. No differences were observed between the follow-up measurements $(p=1.000)$. However, this variable differed significantly in the post-adoption measurement, compared to the follow-up measurements $(p=.000)$. The descriptive data show that while the mean score of this strategy was the highest in the pre-adoption measurement, there was an increase in the mean score in the post-adoption test, compared to measurement moments 2 and 3.

For teachers, the learner-centred approaches interaction $(F(3,243)=8.86, p=.000)$, game-based learning $(F(3,244)=4.05, p=.008)$, and collaboration $F(3,244)=7.71, p=.000$ ) were significant. Concerning interaction, pairwise comparisons using the Bonferroni test show that pre-adoption expectations were significantly higher, compared to follow-up measurement $2(p=.008)$ and $3(p=$ .015). No significant difference was found between the two follow-up measurements $(p=1.000)$. We found no significant difference $(p=.829)$ between the preliminary expectations in the pre-adoption measurement and the post-adoption measurement after five years, indicating that expectations regarding the use of this instructional method for tablets were met. Regarding the instructional format game, a significant difference was measured only between the first and the third measurement moment $(p=.015)$; thus, the descriptive results (see Table 2 ) show a decline in the mean score between these two moments. However, no difference could be found between the pre- and postadoption measurements $(p=1.000)$. Finally, concerning collaboration, pairwise comparisons indicate that while the expectations are significant higher compared to the follow-up measurements $(p<.05)$, no difference between the first and last measurement $(p=1.000)$, signifying that the prior-to adoption expectations were met after five years.

Furthermore, when taking 'actor' as a fixed variable in the analysis, results indicate a difference between the perspectives of students and teachers about the use of tablets (Wilks' $\lambda=.88 F(5,2687)=$ $75.60, p=.000)$. With the exception of the instructional format games, teachers reported higher tablet use for instruction, interaction, assignment, and collaboration compared to students $(p<.05)$. 
Table 2. Descriptive data concerning student and teacher expectations and actual use.

\begin{tabular}{l|c|c|c|c|c}
\hline \hline $\begin{array}{l}\text { Instructional } \\
\text { strategies }\end{array}$ & Actor & $\begin{array}{c}\text { Wave 1 } \\
\text { Expectations } \\
\mathrm{M}(\mathrm{SD})\end{array}$ & $\begin{array}{c}\text { Wave 2 } \\
\text { Actual use } \\
\mathrm{M}(\mathrm{SD})\end{array}$ & $\begin{array}{c}\text { Wave 3 } \\
\text { Actual use } \\
\mathrm{M}(\mathrm{SD})\end{array}$ & $\begin{array}{c}\text { Wave 4 } \\
\text { Actual use } \\
\mathrm{M}(\mathrm{SD})\end{array}$ \\
\hline \multirow{2}{*}{\begin{tabular}{l} 
Lecture (/12) \\
\cline { 2 - 6 }
\end{tabular}} & Students & $6.99(.09)$ & $6.37(.10)$ & $6.10(.10)$ & $6.17(.11)$ \\
\cline { 2 - 6 } & Teachers & $8.54(.34)$ & $8.79(.38)$ & $9.01(.36)$ & $9.33(.53)$ \\
\hline $\begin{array}{l}\text { Interaction } \\
\text { (/12) }\end{array}$ & Students & $6.37(.11)$ & $4.04(.12)$ & $3.75(.12)$ & $5.61(.13)$ \\
\cline { 2 - 6 } $\begin{array}{l}\text { Assignment } \\
\text { //12) }\end{array}$ & Teachers & $6.53(.37)$ & $4.63(.41)$ & $4.81(.39)$ & $7.47(.58)$ \\
\cline { 2 - 6 } & Students & $7.49(.11)$ & $5.89(.12)$ & $5.77(.12)$ & $6.53(.13)$ \\
\hline Game (/12) & Students & $5.30(.11)$ & $3.05(.11)$ & $2.81(.11)$ & $3.05(.13)$ \\
\cline { 2 - 6 } & Teachers & $3.50(.38)$ & $2.17(.42)$ & $1.80(.39)$ & $3.23(.58)$ \\
\hline $\begin{array}{l}\text { Collaboration } \\
\text { (/12) }\end{array}$ & Students & $6.91(.13)$ & $4.49(.14)$ & $4.58(.14)$ & $5.88(.15)$ \\
\cline { 2 - 6 } & Teachers & $7.77(.51)$ & $4.84(.57)$ & $5.10(.53)$ & $7.68(.79)$ \\
\hline \hline
\end{tabular}

\subsection{RQ2: How are the tablets currently being used in the post-adoption measurement?}

To observe whether certain instructional methods are more frequently used than others in the postadoption test (wave 4), a repeated measures ANOVA was conducted.

For students, repeated measures were significant (Wilks' $\lambda=.36 F(4,498)=222.76, p=.000$ ), where a difference between the amount of used instructional strategies was measured. Post-hoc comparisons show no significant difference between the formats lecture and collaboration $(p=.469)$, or between interaction and collaboration $(p=.730)$. Based on the descriptive data (see Table 2), while mean scores were not very high (maximum score 12), students stated in the final measurement that assignment was the most-used instructional strategy involving the tablet. The same frequency was recorded for giving lectures, interaction exercises, and collaborative learning using the tablet. Only games are significantly lower used compared to the other four instructional strategies $(p<.05)$.

For teachers, the repeated measures analysis was also significant in the final measurement (Wilks' $\lambda=$ $.27 F(4,29)=20.00, p=.000$ ). The mean scores were not very high (maximum score 12), and pairwise comparisons show no difference between giving lectures, interaction exercises, assignments, and collaboration tasks using the tablet. In line with students' results, games were used at a significantly lower rate.

In line with research question one, when taking into account 'actor' as a between-subject in the analysis, a difference arises between student and teacher reporting concerning the use of tablets (Wilks' $\lambda=.94 F(4,530)=8.22, p=.000)$. Based on the descriptives, teachers reported a higher tablet use for all the instructional strategies, compared to students. 


\subsection{RQ3: Is there a relation between the use of tablets and individual and contextual teacher characteristics?}

A multivariate analysis of variance with instructional strategies as dependent variables, and including individual (age, gender) and context-level (grade) variables, was conducted to measure the impact of both individual and contextual teacher characteristics across the four waves. While teachers' gender did not play a significant role in teachers' use of tablets (Wilks' $\lambda=.99, F(5,242)=.61, p=.690$ ), the age of teachers was significant for all instructional strategies (lecture $F(1,245)=7.97, p=.005, \mathrm{~B}^{*}=$ .18 ; interaction $F(1,245)=14.88, p=.000 ; \mathrm{B}^{*}=-.24$; assignment $F(1,245)=12.06, p=.001, \mathrm{~B}^{*}=-.22$; game $F(1,245)=5.80, p=.017, B^{*}=-.15$; collaboration $\left.F(1,245)=6.47 p=.012, B^{*}=-.16\right)$. Moreover, as indicated by the standardised beta coefficients, the older the teachers were, the less often the tablets were used for instructional strategies. Finally, grade was significant for the instructional format game $(F(2,243)=12.80, p=.000)$, and the descriptive data show that students at grade 7 to 8 used this strategy more often $(M=4.13, S D=.37)$, compared to the older students of grades 9 to $10(M=2.36, S D=.43)$, or grades 11 to $12(M=1.72, S D=.31)$.

\section{DISCUSSION AND CONCLUSION}

Due to their features, tablets are promising tools that can enhance student-centred learning [6]. However, currently, research that focuses on the use of tablets are still at an early stage [13], and the available research reports primarily on the use of tablets for a relatively short time-period [20]. Based on these shortcomings, the current research focused on a full-scale tablet implementation and the instructional strategies employed in a school that introduced the use of tablets in 2012. Based on research conducted by Becker and Ravitz [16], who state that it takes some time for teachers to attain expertise, the results of Ifenthaler et al. [10] suggest that longitudinal research is needed, because if teachers develop expertise over a prolonged period, this may lead to a change in terms of adopting more student-oriented teaching practice. Given this information, the following research questions were central in this research: 1) Does the use of the different instructional strategies change over the time period of five years? 2) How are tablets currently used in the post-adoption measurement? Additionally, because research focusing on technology-enhanced learning highlights the importance of taking teachers' characteristics into account $[17,18,19,20]$, (3) the relation between the use of tablets and individual and contextual teacher characteristics was also investigated.

As a conclusion on the first research question, the results show a noticeable evolution concerning the amount and type of tablet use for both teachers and students. Regarding students, pre-adoption expectations about the five instructional strategies were significantly higher, compared to the other three measurement moments. Another positive evolution is that the learner-centred approaches, interaction, assignment, and collaboration, were significantly higher in the post-adoption test, compared to the two follow-up measurements. Teachers' prior expectations about using the tablet for more learner-centred approaches were, following a decline in the follow-up studies, met after five years. These results show that while high expectations towards the didactical use of tablets were not met in the follow-up measurements, and tablets were mainly used to support teacher-centred education, this pattern changed over time. Moreover, in the post-adoption test, the use of learnercentred approaches arose. The results of this research show that while implementing technology does not directly lead to a radical change in didactic teaching methods [8], according the hypothesis of Ifenthaler et al. [10], the longer and more intensive use of tablets led to more student-oriented practices. The reason for students' pre-adoption expectations being significantly higher compared to other measurements may be found in the notion that students may have overestimated the use of tablets, thus having too high expectations which could not be reached. However, the fact that the instructional strategies, that were increased in students' data in the final measurement moment, compared to the two previous follow-up studies, are positive results, and confirm the uptake of using the tablets for more learner-centred approaches. In addition, the variable 'actor' is also significant, indicating that teachers' perspectives about the amount of tablet use are different when compared to those of students. Moreover, based on the descriptives, teachers in general reported higher tablet use, compared to students. This finding is interesting, and highlights the need for taking a multi-stakeholder perspective into account. Several reasons that may explain the difference between student and teacher perspectives can be formulated. Firstly, while teachers seemed to believe they used tablets more intensively, students may have been more sceptical about teachers' use of tablets and may believe that tablets can be used more frequently, compared to their current use. Secondly, because 
not all teachers cooperated in this research, it is possible that teachers who were not motivated to participate in this research were likely less interested in the use of tablets. Thirdly, the way of measuring the amount of tablet use can also be a reason for the difference between teachers' and students' results; while students had to complete the questionnaire for all the different subjects, teachers only answered these questions for their own course. Regarding the second research question, no difference was found regarding the amount of lectures given, interaction exercises, or collaboration tasks. This finding indicates that tablets are currently being used in this school to promote both teacher-centred and learner-centred approaches, despite tablets not being used to promote game-based learning. These findings are in line with those of Henderson and Yeow [5], and a review by Sung et al. [11], who showed that tablets can be used to foster learner-centred education, and to facilitate assignment activities and collaborative learning. Finally, as an answer to the third research question, both individual-related and contextual-related teacher characteristics were found to play a significant role. Moreover, the results showed that the older the teachers were, the less tablets were integrated during the different instructional strategies. This is fully in line with previous research [10], which also found a negative relation between age and computer use. In addition, in contrast to Zhao and Frank [24], in the current research, teachers used more game-based learning approaches, particularly in lower grades. The reason for this is that there is likely more material available for promoting game-based learning in lower grades; alternatively, learning material for lower grades is less complex compared to higher grades, which allows for a game-based learning approach to be employed in lower grades.

While acknowledging the limitations of this study in terms of the number of teachers that completed the final questionnaire, or the way in which instructional strategies were measured, these results highlight that using a tablet did not radically prohibit all the rather traditional teaching practices. It is a positive evolution that, compared to follow-up studies, found a balance between the different instructional strategies. Furthermore, the fact that in the post-adoption measurement, significantly more learner-centred strategies were used, and that these met teachers' expectations, are interesting findings. Moreover, students' prior-to-adoption expectations were extremely high, and apparently, they faced more difficulties in terms of estimating the actual use of tablets. Consequently, there was a significant decline of the actual use in the follow-up measurements; fortunately, however, learnercentred strategies increased in the post-adoption measurements. Both teachers and students reported multidimensional use of the tablets to promote collaboration, complete assignments, and engage in interaction. To conclude, these results provide meaningful insight into the dynamic evolution of tablet use over a period of five years, with experienced stakeholders, which is a requirement in research focusing on the didactical value of this tool. While this research serves as a first step into longitudinal research about the use of technology, avenues for further research remain open. A next step is to examine the didactic impact according to the variety of way tablets can be used in relation to student variables such as motivation and knowledge acquisition, thereby helping to formulate didactic guidelines on how tablets can empower teaching and learning practices.

ACKNOWLEDGEMENTS We would like to thank the staff, teachers and students from SintJozef Sint-Pieter Blankenberge, Flanders for participating in this research.

\section{REFERENCES}

[1] G. Falloon, "Young students using iPads: App design and content influences on their learning pathways", Computers \& Education, vol. 68, pp. 505-521, 2013.

[2] B. Clarke, \& S. Svanaes, "An updated Literature Review on the Use of Tablets in Education", Family, Kids \& Youth, 2014.

[3] H. Montrieux, R. Vanderlinde, T. Schellens, \& L. De Marez, "Teaching and Learning with Mobile Technology: A Qualitative Explorative Study about the Introduction of Tablet Devices in Secondary Education", Plos One, vol.10, no.12, 2015.

[4] M. Van't Hooft, "The potential of mobile technologies to connect teaching and Learning inside and outside the classroom", In Emerging technologies for the classroom (C. Mouza \& N.Lavigne, Eds.), pp. 175-186, NewYork: Springer, 2013.

[5] S. Henderson, \& J. Yeow, "iPad in education: A case study of iPad adoption and use in a primary school", In Proceedings of the 45th Annual Hawaii International Conference on System Sciences (R. H. Sprague, Ed.), pp. 78-87. New York,: IEEE, 2012. 
[6] K. Melhuish, \& G. Falloon, "Looking to the future: M-learning with the iPad", Computers in New Zealand Schools, vol. 22, no. 3, pp. 1-16, 2010.

[7] P. Ertmer, "Addressing First- and Second-Order Barriers to Change: Strategies for Technology Integration", Educational Technology Research and Development, vol. 4, no.4, pp. 47-61, 1999.

[8] P. Ertmer, A. Ottenbreit-Leftwich, "Removing obstacles to the pedagogical changes required by Jonassen's vision of authentic technology-enabled learning”, Computers \& Education, vol. 64, pp. 175-182, 2013.

[9] S. Prestridge, "Examining the shaping of teachers' pedagogical orientation for the use of technology", Technology, Pedagogy and Education, vol. 26, no. 4, pp. 1-15, 2017.

[10] D. Ifenthaler, \& V. Schweinbenz, "The acceptance of Tablet-PCs in classroom instruction: The teachers' perspectives", Computers in Human Behavior, vol. 29, no. 3, pp. 525-534, 2013.

[11] Y. Sung, K. Chang, T, Liu, "The effects of integrating mobile devices with teaching and learning on students' learning performance: A meta-analysis and research synthesis", Computers \& Education, vol. 94, pp. 252-275, 2016.

[12] D.H. Jonassen, \& T.C. Reeves, "Learning with technology: Using computers as cognitive tools", In Handbook of research for educational communications and technology (D. H. Jonassen, Ed.), 1996.

[13] B. Haßler, L. Major, \& S. Hennessy, "Tablet use in schools: a critical review of the evidence for learning outcomes", Journal of Computer Assisted Learning, vol. 32, no. 2, pp. 139-156, 2016.

[14] K. Burden, P. Hopkins, T. Male, S. Martin, and C. Trala, iPad Scotland Evaluation, University of Hull, 2012.

[15] W. Clark \& R. Luckin, What the research says. iPads in the classroom. London: Institute of Education University of London, 2013.

[16] H.J. Becker, \& J. Ravitz, "The influence of computer and internet use on teachers' pedagogical practices and perceptions", Journal of Technology Education, vol. 31, pp. 356-84, 1999.

[17] C-S. Ong, J.Y. Lai, "Gender differences in perceptions and relationships among dominants of elearning acceptance", Computers in Human Behavior, Vol. 22, no. 5, pp. 816-829, 2006.

[18] J., Mueller, E. Wood, T. Willoughby, C. Ross, \& J. Specht, "Identifying discriminating variables between teachers who fully integrate computers and teachers with limited integration", Computers \& Education, vol. 51, no. 4, pp. 1523-1537, 2008.

[19] E. Tezci, "Teachers' effect on ict use in education: the Turkey sample", Procedia - Social and Behavioral Sciences, vol. 1, no. 1, pp. 1285-1294, 2009.

[20] G., Sang, G., M. Valcke, J. van Braak, \& J. Tondeur, "Student teachers' thinking processes and ICT integration: predictors of prospective teaching behaviors with educational technology", Computers \& Education, vol. 54, no. 1, pp. 103-112, 2010.

[21] F. Inan, \& D. Lowther, "Factors affecting technology integration in K-12 classrooms: A path model", Educational Technology Research and Development, vol. 58, pp. 137-154, 2010.

[22] T. Teo, "Modelling technology acceptance in education: a study of pre-service teachers", Computers \& Education, vol. 52, no.2, pp. 302-312, 2009.

[23] M.J. Brosnan, M. Davidson," Psychological Gender Issues in Computing. Gender, work and Organization", vol. 3, no. 1, pp. 13-25, 1996.

[24] Y. Zhao \& K. Frank, "Factors affecting technology uses in schools: An ecological perspective", American Educational Research Journal, vol. 40, no. 4, pp. 807-840, 2003.

[25] K. Swan, M. van 't Hooft, A. Kratcoski, \& D. Unger, "Uses and effects of mobile computing devices in K-8 classrooms", Journal of Research on Technology in Education, vol. 38, no. 1, 99112, 2005.

[26] L. Corrin, S. Bennett, \& L. Lockyer, L. "Digital natives: Everyday life versus academic study", In Proceedings of the Seventh International Conference on Networked Learning, pp. 643-650, Lancaster University, 2010. 
[27] H. Montrieux, C. Courtois, A. Raes, T. Schellens, \& L. De Marez, "Mobile learning in secondary education: teachers' and students' perceptions and acceptance of tablet computers", International Journal of Mobile and Blended Learning, vol. 6, no. 2, pp. 26-40, 2014.

[28] P. Hoogeveen, \& J. Winkels, Het didactisch werkwoordenboek. Variatie en differentiatie in de praktijk. Assen: Koninklijke Van Gorcum BV, 2015. 